\title{
The impact of parental investment on lifetime reproductive success in Iceland
}

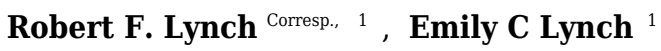 \\ ${ }^{1}$ Department of Anthropology, University of Missouri, Columbia, Missouri, United States \\ Corresponding Author: Robert F. Lynch \\ Email address: robertflynch@gmail.com
}

Background: Demonstrating the impact that parents have on the fitness of their children is a crucial step towards understanding how parental investment has affected human evolution. Parents not only transfer genes to their children, they also influence their environments. By analyzing reproductive patterns within and between different categories of close relatives, this study provides insight into the genetic and environmental effects that parents have on the fitness of their offspring.

Methods: We use data spanning over two centuries from an exceptionally accurate Icelandic genealogy, Íslendingabók, to analyze the relationship between the fertility rates of close relatives. Also, using genetic data, we determine narrow sense heritability estimates $\left(h^{2}\right)$ to further explore the genetic impact on lifetime reproductive success. Finally, we construct four simulations to model the expected contribution of genes and resources on reproductive success.

Results: The relationship between the reproduction of all full sibling pairs was significant and positive across all birth decades $(r=0.19)$ while the reproductive relationship between parents and offspring was often negative across many decades and undetectable overall ( $r=0.00)$ (Figure 1, Table 1). Meanwhile, genetic data among 8,456 pairs of full siblings revealed a narrow sense heritability estimate $\left(h^{2}\right)$ of 0.00 for lifetime reproductive success. A resources model (following the rule that resources are transmitted from parents to children, distributed equally among siblings, and are the only factor affecting reproductive success) revealed a similar trend: a negative relationship between parent and offspring reproduction ( $r=-0.35$ ) but a positive relationship among full siblings $(r=0.28)$. The relationship between parent and offspring lifetime reproductive success (LRS) and full sibling LRS was strongly and positively correlated across time $(r=0.799, p<0.001)$. Similarly, the LRS among full siblings was positively correlated with both the LRS among half siblings $(r=0.532, p=0.011)$ and the relationship between the LRS of aunts and uncles with their nieces and nephews ( $r=0.438, p=0.042)$.

Discussion: We show that an individual's lifetime reproductive success is best predicted by the reproduction of their full and half siblings, but not their parents, grandparents or aunts and uncles. Because all siblings share at least one parent, we believe parental investment has had an important impact on fitness. Overall, these results indicate that direct parental investment, but not genes, is likely to have had an important and persistent impact on lifetime reproductive success across more than two centuries of Icelandic history. Brit 
1 The impact of parental investment on lifetime reproductive success in Iceland

2 Robert F. Lynch ${ }^{1}$, Emily C. Lynch ${ }^{1}$

$3{ }^{1}$ Department of Anthropology, University of Missouri, Columbia, Missouri, USA

4

5 Corresponding Author:

$6 \quad$ Robert Lynch

$7 \quad$ Email address: robertflynch@gmail.com

8

\section{Abstract}

\section{Background:}

11 Demonstrating the impact that parents have on the fitness of their children is a crucial step

12 towards understanding how parental investment has affected human evolution. Parents not only

13 transfer genes to their children, they also influence their environments. By analyzing

14 reproductive patterns within and between different categories of close relatives, this study

15 provides insight into the genetic and environmental effects that parents have on the fitness of

16 their offspring.

17 Methods: We use data spanning over two centuries from an exceptionally accurate Icelandic

18 genealogy, Íslendingabók, to analyze the relationship between the fertility rates of close

19 relatives. Also, using genetic data, we determine narrow sense heritability estimates $\left(\mathrm{h}^{2}\right)$ to

20 further explore the genetic impact on lifetime reproductive success. Finally, we construct four

21 simulations to model the expected contribution of genes and resources on reproductive success.

22 Results: 
23 The relationship between the reproduction of all full sibling pairs was significant and positive

24 across all birth decades $(r=0.19)$ while the reproductive relationship between parents and

25

26

27 offspring was often negative across many decades and undetectable overall $(\mathrm{r}=0.00)$ (Figure 1 , Table 1). Meanwhile, genetic data among 8,456 pairs of full siblings revealed a narrow sense heritability estimate $\left(\mathrm{h}^{2}\right)$ of 0.00 for lifetime reproductive success. A resources model (following the rule that resources are transmitted from parents to children, distributed equally among siblings, and are the only factor affecting reproductive success) revealed a similar trend: a negative relationship between parent and offspring reproduction $(r=-0.35)$ but a positive relationship among full siblings $(\mathrm{r}=0.28)$. The relationship between parent and offspring lifetime reproductive success (LRS) and full sibling LRS was strongly and positively correlated across time $(\mathrm{r}=0.799, \mathrm{p}<0.001)$. Similarly, the LRS among full siblings was positively correlated with both the LRS among half siblings $(r=0.532, \mathrm{p}=0.011)$ and the relationship between the LRS of aunts and uncles with their nieces and nephews $(\mathrm{r}=0.438, \mathrm{p}=0.042)$.

Discussion: We show that an individual's lifetime reproductive success is best predicted by the reproduction of their full and half siblings, but not their parents, grandparents or aunts and uncles. Because all siblings share at least one parent, we believe parental investment has had an important impact on fitness. Overall, these results indicate that direct parental investment, but not genes, is likely to have had an important and persistent impact on lifetime reproductive success across more than two centuries of Icelandic history.

\section{Introduction}

Parental investment (PI) is crucial for the success and survival of offspring in many species (Trivers 1972). Direct parental investment may vary in form, amount, and duration, which can affect offspring survival, growth, and development. To tease apart direct parental 
46 investment from genetic contributions, heritability estimates can be used to measure the

47 respective effects that genes and the environment have on a given phenotype. These proportions

consider the fraction of the phenotypic variation between individuals in a population that results from genotypes (Falconer, 1989; Raj and Van Oudenaarden, 2008).

$$
\text { There are several ways to estimate heritability. The simplest method is to either compare }
$$

parent and offspring traits (the mid-parent-offspring regression) or compare the similarity of traits between full siblings (full sibling's correlation). Higher correlations between the traits of family members suggests higher heritability (Visscher et. al., 2008; Visscher et. al., 2006).

These estimates, however, represent an upper limit for the effect of genes on a trait and assume there is no environmental effect (Falconer, 1989). It should be noted that heritability estimates are also biased by sources of non-additive genetic variance (e.g. dominance and epistasis). For example, heritability estimates obtained from parent-offspring and full-sibling regressions include dominance variance, while this is not the case for estimates obtained from half-siblings. In the past, the most common technique for estimating heritability in humans has been the twin design (Lynch and Walsh, 1998) while the "animal model", in which a pedigree is entered into a restricted maximum likelihood (REML) model, has gained popularity over recent decades for non-human species (Henderson, 1975; Hill et. al., 2008; Visscher et. al., 2008; Wilson, et. al., 2010). Animal models tend to yield slightly lower heritability estimates than those obtained from parent-offspring regressions because they are less biased by common environments shared by first order relatives (i.e., parent-offspring and full sibling dyads) (Akesson et. al., 2008). Different methods introduce different biases and the impact of common environments inflating heritability estimates are of particular concern when studying humans because we often share complex and overlapping environments with close relatives (Visscher et. al., 2008). More 
69 recently, detailed genetic data can be used to sidestep these issues and produce estimates

70 unbiased by shared environments. By taking advantage of the random segregation of parental

71 alleles (e.g. full siblings share a mean coefficient of relatedness of 0.5 but exhibit considerable

72 variance around this mean $(\underline{\mathrm{SD}+/-4.0 \%)})$, researchers can generate extremely accurate estimates

73 of both environmental and genetic effects (Visscher et. al., 2008).

74 Although heritability estimates can be good for measuring the relative contribution of genes

75 and environments, they are often confounded when environments are shared by kin. This is

76 because differences in life history outcomes between individuals, especially close relatives, can

77 result from both environmental and genetic effects (Fisher, 1930; Kosova et. al., 2010).

78 Furthermore, heritability estimates obtained by comparing the traits of relatives are differentially

79 and upwardly biased, depending on the degree to which the relatives share common

80 environments.

81 Heritability estimates obtained from the genotypes of relatives, such as full siblings, can

82 therefore be used to identify the precise proportion of a trait resulting from additive genetic

83 variance. In other words, we can use genetic data to determine exactly how much of a given

84 phenotype results from shared genes and how much is due to shared environments. Meanwhile,

85 comparing traits between different classes of relatives (e.g. among siblings or between parents

86 and offspring) can help to partition the remaining environmental variance into various

87 components. Therefore, the degree to which estimates between different categories of relatives

88 are biased can be used to provide insight into which environmental factors (e.g. parents, common

89 household and geographic location) have the largest effects on a given phenotype. In sum,

90 comparing traits between relatives who share a different degree of genetic relatedness and

91 different types of environments can help partition these environmental effects. 
92 The aim of this study was to determine the impact that parents have on the lifetime

93 reproductive success (LRS) of their children. To date, a small number of studies have been able

94 to use large genealogical databases to estimate the heritability of reproductive success. One

95 study of a late $19^{\text {th }}$ century population from Utah showed that increasing parental reproduction

96 reduced the reproductive success of offspring (i.e. the more siblings that individuals had the

97 lower their LRS) (Penn and Smith, 2007). High heritability's were obtained for several key life-

98 history traits (e.g. fecundity, interbirth interval, age at last reproduction, and adult longevity)

99 from an animal model for females, but not males, in a preindustrial Finnish population in one

100 study (Pettay et. al., 2005) and for both sexes in another (Bolund et. al., 2013). These estimates

101 were also seen to persist after the demographic transition (after 1880 in Finland) (Bolund, et. al.,

102 2015). Another study of alpine communities in Tyrol, Italy found moderate to low heritability of

103 LRS $\left(\mathrm{h}^{2} \sim 0.07\right)$ for both males and females, but these estimates did not consider the shared

104 environmental effects of a common household or shared parents (Gögele et. al., 2011). Finally,

105 age at first reproduction of females in a pre-industrial French Canadian population was shown to

106 decline by 4 years over a 140-year period and heritability estimates derived from an animal

107 model indicated that this change was likely to have arisen from genetic changes (Milot et. al.

108 2011).

109 Using an exceptionally accurate and large database, spanning over two centuries, we examined 110 the relationship between parental LRS and offspring LRS. Because parents and offspring share

111 half their genes, we predicted that if genes have had an important effect on reproduction, then the

112 LRS of ones' parents will predict an individual's LRS. Meanwhile, if parental investment (PI; cf

113 Trivers, 1972) and the environment provided by parents (e.g. a common household) have had a

114 stronger impact on reproductive success, then full siblings will predict ones LRS. This is 
115 because, in addition to sharing the same average degree of relatedness as parents and offspring

$116(\mathrm{r}=0.5)$, full siblings also share parents. Furthermore, we predicted that if these relationships are

117 strongly influenced by the environment that parents provide (e.g. a common household) they will

118 respond to environmental volatility and should change over time. This study examined the

119 effects that different categories of first (full siblings and parents) and second degree relatives

120 (half siblings, grandparents and aunts and uncles) have had on an individual's LRS across over

121 two hundred years of Icelandic history.

122 Materials and Methods

123 The database:

124 We used an Icleandic genealogy, also known as Íslendingabók, to test our predictions.

125 Íslendingabók has several important advantages over other genealogical databases. First, it is a 126 population-based database that contains information about approximately 600,000 of the one

127 million individuals estimated to have ever inhabited Iceland (Gudmundsson et. al., 2000). A

128 population-based genealogy is advantageous because there is less of a chance of imposing a

129 sampling bias. Using a national census to generate demographic information, reduces the

130 possibility of over or under report any particular group (Moorad et. al., 2011). Second, the

131 database is extremely accurate as it includes all living Icelanders and most of their ancestors. An

132 examination of mitochondrial DNA shows a maternal accuracy rate of $99.3 \%$ (Sigurardottir et.

133 al., 2000) while the mistakenly assigned paternity error rate is estimated to be less than $1.5 \%$

134 (Gudmundsson et. al., 2000). A third advantage of Íslendingabók is that it is based on a

135 relatively isolated population. This allows for a more accurate genealogical analysis across

136 multiple generations. Finally, because Iceland's economy did not undergo industrialization until

137 after World War II, there are extensive life history data on individuals who reproduced prior to 
138 the massive changes in mortality and fertility rates that characterize the demographic transition -

139 - the process by which high fertility and mortality rates are replaced by low fertility and mortality 140 rates (McNicoll, 1992).

141 The first national census in Iceland was taken in 1703 (Karlsson, 2000), and these data were 142 often regarded as the most accurate (Gundarson, pers. comm.). Therefore, all our analyses were 143 restricted to individuals born after 1700 . Our analyses were also limited to individuals who were 144 born before the industrialization of Iceland, circa 1920. This was done for two reasons. First, 145 the demographic transition may have fundamentally changed patterns of population growth that 146 had been more typical of ancestral human populations (Barthold et. al., 2012). Second, the 147 expected positive relationship between resources and reproduction is often decoupled after the 148 demographic transition, whereby poverty is associated with high fertility rates (McNicoll, 1992). 149 Fertility data:

150 Individual LRS was the primary dependent variable, but mean fertility rates fluctuated 151 considerably across time. For example, average fertility rates for individuals born between 1810 152 and 1819 peak at 3.12 children but drop to 1.98 only thirty years later (1850-1859). Therefore, 153 all LRS values for all individuals were first log transformed and standardized by the decade in 154 which the individual was born ([log transformed value - mean of decade]/ standard deviation of 155 decade). This transformation made the reproduction of individuals less dependent on changes in 156 mean family size across birth decades, so that effective comparisons could be made across time 157 (Helgason et. al. 2008).

158 Heritability estimates among relatives:

159 Although heritability estimates based on precise coefficients of relatedness among full siblings 160 can be used to obtain accurate and unbiased estimates of the genetic impacts of parents, 
161 distinguishing the effect of parental investment (PI) from other environmental factors (e.g.

162 shared household, community or geographic region) is more difficult. One way to isolate the

163 effects of PI on offspring LRS, however, is to compare the reproductive similarity of close

164 relatives across varying degrees of social and genetic relatedness. Parents, children, and full

165 siblings, for instance, all share a coefficient of relatedness (r) of 0.5 and are all first-degree

166 relatives while half-siblings, aunts-uncle and nieces and nephews, and grandparents and their

167 grandchildren are all second-degree relatives and share an average coefficient of relatedness (r)

168 of 0.25 . Comparing the degree to which different types of relatives with the same coefficients of

169 relatedness share fitness outcomes may yield insights into the impacts that different

170 environments have on reproduction.

171 For example, although members of the immediate family are all first-degree relatives and are

172 therefore all related by the same coefficient of relatedness, the environments they share are

173 different. For example, full siblings share parents, while parents and their children do not.

174 Meanwhile comparing relatives with different coefficients of relatedness who often share similar

175 environments (e.g. full siblings $(r=1 / 2)$ and half siblings $(r=1 / 4))$ may also produce insights.

176 Therefore, comparing different types of relatives both between and within different categories of

177 genetic and social relatedness may shed light on the effects of sharing different types of

178 environments on an individual's LRS. This is because heritability estimates based on

179 correlations between relatives depend critically on the assumption that the environments shared

180 between relatives with the same mean coefficients of relatedness are the same across all social

181 categories and it is often unclear which relatives share a common environment. For example, do

182 parent-offspring pairs have the same amount and type of environmental sharing as siblings? 
183 (Zatlen, 2013). In short, if different types of relatives exist in different environments, heritability

184 estimates will be biased (Thomas et. al., 2000; Wray and Visscher, 2008, Zaitlen et. al., 2013).

185 In this study, broad sense heritability estimates $\left(\mathrm{H}^{2}\right)$ for LRS were obtained from the historic

186 genealogical data by correlating the traits of two types of first degree relatives (coefficient of

187 relatedness, $\mathrm{r}=1 / 2$ ): parents with their children and full siblings. Parent-offspring heritability was

188 measured by correlating the mid-parent standardized reproduction or lifespan (e.g. [mothers LRS

189 +fathers LRS] /2) with the standardized reproduction of their offspring. Full sibling heritability

190 was measured by correlating an individual's standardized LRS with the mean of the standardized

191 LRS of all his or her full siblings. Correlations of the LRS of individuals with second degree

192 relatives ( $\mathrm{r}=1 / 4$; aunts and uncles, grandparents, and half siblings) were also obtained. All

193 correlations between the LRS of relatives were calculated as the proband's standardized LRS to

194 the mean of the standardized LRS of all his or her relatives in the comparison group (e.g. mean

195 LRS of all aunts and uncles). All correlations were weighted by family size to provide equal

196 weight to each group of relatives. For example, in determining the correlation amongst full

197 siblings, individuals who had 4 full siblings were weighted 1/4 as much as those who had only

198 one. Using SPSS, the 'weight cases by' command was used, the frequency of individuals for

199 each type of relative was entered.

200 Simulations:

201 Three models were constructed in Visual Basic to simulate the impact of parental investment and

202 genes on offspring reproduction. Specifically, the models were designed to simulate the effects

203 of parents transferring a finite amount of investment (i.e. that which is diluted by additional

204 offspring) called 'resources', and or a fixed (i.e. undiluted by one's number of offspring) effect 
205 which we called 'genes'. These results were then compared with the actual results from the 206 genealogical data to gain insight into which model best approximated the data.

207 Model 1, The Null Model: This model assumed neither genes nor resources played any role in

208 the number of offspring an individual produced. Reproduction followed a random Poisson

209 distribution and was based solely on certain fixed parameters, including the mean number of

210 offspring per generation and the standard deviation of each generation's size.

211 Model 2, The Resources Model: Here, the number of children, and hence grandchildren, that an

212 individual produced was tied to the number of resources that the F1 generation transmitted to 213 their offspring.

214 Model 3, The Genetic Model: This model was based on Mendelian inheritance, in which the

215 number of children and grandchildren produced was determined by the alleles they inherited

216 from each of their parents.

217 Model 4, The Genes and Resources Model: A simulation was used to explore the impact of 218 both genes and resources on an individual's reproduction.

All reproductive values (LRS) were log transformed and standardized [(log transformed value - mean of decade)/ standard deviation of decade)] by the individual's birth decade.

Pearson correlations on the y-axis are between mid-parent (mother and fathers LRS average) and offspring LRS and among full siblings (each siblings LRS was correlated with the average of all their full siblings) for each decade shown on the x-axis (1700-1919). Correlations were weighted by number (e.g. if an individual had either 10 full siblings or 10 children they each were each statistically weighted at 0.1 ).

Results of the resource model and the genetic model were based on 200 simulations

227 (Table 2). There were 1,000 parents (F1 generation) in each simulation with an average 
228 reproduction per generation of two and a genetic fitness set equal to one. The resources

229 available in the F1 generation had a mean of one with a standard deviation of two and the mean

230 number of children per generation was set equal to two.

$231 \quad$ Family size varied widely across and within decades and because individuals within a

232 particular family were not independent, larger families were expected to inflate correlations. We

233 addressed this problem by randomly choosing the reproduction of just two children (e.g., the first

234 was equally as likely to be chosen as the 4th). This method ensured larger families were not

235 contributing more measurements in the regressions and within group correlations than smaller

236 families. For the mid-parent (the average of the mother and fathers LRS) offspring correlations,

237 we regressed the average number of children (F2 generation) from each set of parents on the

238 average number of grandchildren of two randomly selected children (F3 generation). This

239 process of randomly selecting two individuals and averaging their reproduction eliminated the

240 erroneous inflation of both the full sibling and parent-offspring correlations from the results of

241 the simulations. This same problem was solved for the genealogical data by standardizing LRS

242 within everyone's birth decade and statistically weighting the data by the number of individuals

243 in each class of relatives (e.g., half siblings, number of grandchildren).

244 Genetic data:

245 Genetic data for some individuals who were alive after 1996 were available from deCode

246 genetics and were based on approximately 300,000 single nucleotide polymorphisms (SNP's) for

247 each genotyped individual. Therefore, accurate coefficients of relatedness were obtained for

248 8,456 pairs of full siblings and were entered into a restricted maximum likelihood (REML)

249 model. The lifetime reproductive success of these individuals was standardized by sex, birth

250 year and geographic region. This was only done for the genotyped individuals, however, 
251 because geographic region was not available for individuals in the historic dataset. Full siblings

252 are related, on average, by a coefficient of relatedness of $1 / 2$. Due to the process of meiosis,

253 however, there are small but significant differences in coefficient of relatedness between them.

254 For example, one pair of full siblings may be related at $\mathrm{r}=0.42$ while another pair is related at

$255 \mathrm{r}=0.58$. These differences in relatedness between full siblings can be used to obtain unbiased

256 narrow sense heritability estimates for any trait. We used a dummy variable $(1=$ full siblings and

$2570=$ all other pairs), to estimate a 'family effect'. In other words, we could distinguish the effect of

258 full siblings, due to their being members of the same family and living together (i.e. an

259 environmental effect), from the effects of genes that full siblings share identical by descent.

260 Because heritability estimates can fluctuate considerably over time as the overall environmental

261 impact on a given phenotype changes, these estimates only provided us with an accurate

262 heritability estimate of LRS for contemporary Iceland.

263 Results

264 The database (Íslendingabók):

265 Analysis of the genealogical data from Íslendingabók for all individuals born between 1700

266 and 1920 revealed that LRS was a strong predictor of the number of grandchildren an individual

267 produced $\left(\mathrm{r}=0.63, \mathrm{p}<10^{-6}\right)$. LRS was therefore considered to be a reasonable proxy for

268 evolutionary 'fitness'.

269 The overall relationship between the reproduction of all full sibling pairs, across all birth years

270 (1700 to 1919) was significant and positive, $r=0.19(\mathrm{p}<0.001)$ while there was no detectable

271 relationship between the reproduction of parents and their offspring, $\mathrm{r}=0.00, \mathrm{p}=0.08$ (Table 1).

272 Nevertheless, across decades the relationship between parent and offspring LRS is correlated

273 with the LRS correlation among full siblings. ( $\mathrm{r}=0.799, \mathrm{p}<0.001$; Figure 1). In other words, the 
274 regressions are positively associated such that when the LRS of parents and offspring is more

275 correlated the relationship among full siblings is also more correlated. Similarly, the correlation

276 of LRS among full siblings was positively correlated with both the LRS among half siblings

$277(\mathrm{r}=0.532, \mathrm{p}=0.011$; Figure 2$)$ and the relationship between the LRS of aunts and uncles with their

278 nieces and nephews ( $\mathrm{r}=0.438, \mathrm{p}=0.042$; Figure 3 ) across decades. On the other hand, there was

279 no detectable relationship between the correlations with one's grandparents LRS and any other

280 category of relative examined (see supplementary materials Table S1). Nor was there any

281 significant association between one's reproductive similarity with aunts and uncles and the

282 reproductive correlation with one's parents across decades $(r=0.166, p=0.46)$.

283 There were major demographic changes that also interacted with these heritability estimates.

284 Average reproduction per decade was negatively associated with the reproductive correlation 285 among full siblings $(\mathrm{r}=-0.603, \mathrm{p}<0.001)$ and the correlation between parents and offspring $(\mathrm{r}=$ -

$2860.44, \mathrm{p}=0.04)$. So as population wide reproductive rates increased, both full sibling and parent287 offspring correlations declined. Population was also positively, but not significantly, correlated 288 with the parent-offspring correlation $(r=0.347, p=0.11)$. Finally, birth interval was weakly, but 289 significantly, correlated with LRS (Pearson's $\mathrm{R}=0.041(\mathrm{p}<0.001)$. In other words, full siblings 290 who were closer in age had more similar fertility.

291

292

293

294

295

296

\section{Simulations:}

Results of the resources model, in which resources that are transmitted from parents to children and distributed equally amongst siblings affects reproductive success, revealed a negative relationship between parent and offspring reproduction but a positive one among full siblings (Table 2). The genetic model, in which offspring inherit their parent's reproduction with some probability, showed nearly identical correlations between the LRS of parents and offspring 
297 and those among full siblings. The full siblings and mid-parent-offspring correlations in LRS are

298 both within 2 standard errors (95\% confidence intervals) of the models simulating "genes and

299 resources", and in a maximum likelihood model the genes and resources model also provides the

300 best fit for the genealogical data (e.g. produces the lowest Akaike Information Criterion score).

301 Genetic data:

302 A restricted maximum likelihood model (REML) entering the precise coefficients of 303 relatedness for 8,456 pairs of full siblings yielded a narrow sense heritability estimate $\left(\mathrm{h}^{2}\right)$ of 3040.137 with a standard error of (0.02). Adding a family effect (i.e. identifying the pairs of full 305 siblings) to the model and allowing it to compete with these coefficients of relatedness, however, 306 revealed a family effect $\left(\mathrm{f}^{2}\right)$ of $0.129(0.03)$ and a genetic effect of $0.00(0.05)$ This suggests that 307 the heritability estimate $\left(\mathrm{h}^{2}=0.137\right)$ was based solely on shared family effects among full 308 siblings and was not due to shared genes. Furthermore, the intra-class correlation of LRS among 309 the 8,456 pairs of full siblings was $\mathrm{r}=0.076\left(\mathrm{~h}^{2}=0.152\right)$ reinforcing results from the REML 310 model and indicating that the heritability estimate of LRS in modern Iceland may be lower than 311 in previous centuries.

\section{Discussion}

313 Analysis of a genealogical database across 220 years of Icelandic history (1700-1920) showed 314 that an individual's lifetime reproductive success (LRS) is strongly predicted by the reproduction 315 of their full siblings but not their parents (Figure 1, Table 1). This study also revealed a 316 negligible heritability $\left(\mathrm{h}^{2}\right)$ for LRS, but a significant shared family effect $\left(\mathrm{f}^{2}\right)$ of parents on the 317 reproduction of their children for the current population based on results from a restricted 318 maximum likelihood model using precise IBD gene sharing (SNPs) amongst full sibling pairs.

319 Finally, results of a model simulating the effects of genes and resources on LRS were most like 
320 the overall results from the genealogy (see comparison of Table 1 and Table 2). Overall, these

321 results suggest that parental investment (PI) has had an important effect on the LRS of children

322 across much of Iceland's history.

323 Why do individuals reproduce like their siblings, but not their parents? Siblings bonds in

324 humans are particularly strong, and brothers and sisters often maintain relationships throughout

325 life (Rodseth et. al., 1991; Chapais, 2011). In hunter gather societies, for example, brothers and

326 sisters commonly co-reside into adulthood (Hill et. al. 2011). During the $18^{\text {th }}$ and $19^{\text {th }}$ century in

327 Iceland, children often shared the same household with their parents after they married (Wall et.

328 al., 1983; Moring, 2003). Therefore, the environments that are shared by siblings throughout

329 development and often past sexual maturity may contribute to similar fertility rates.

330 An individual's LRS is best predicted by the reproduction of full siblings, followed by half

331 siblings, aunts and uncles, grandparents and finally is least like their parents. The relationship

332 amongst the LRS of half siblings who only share one parent is slightly less than half of the

333 relationship among full siblings who share both parents. This is consistent with the view that the

334 environment parents provide, either through direct investment or the effects of a shared

335 household, has an important impact on one's reproduction because full and half siblings share

336 parents, but parents and offspring do not. Meanwhile, the overall undetectable relationship

337 between parent and offspring LRS suggests a low heritability of this trait. The unbiased estimates

338 from the SNP data support this result and suggest a very low $\mathrm{h}^{2}$ in the current population.

339 Although most previous estimates of heritability's using genealogies have shown a more

340 moderate heritability $(\sim 0.10)$ of LRS, these estimates have often been obtained using an animal

341 model in which an entire pedigree is used and are therefore not able to parse specific intra-

342 familial relationships. The low heritability estimates obtained in our study are consistent with 
343 Fishers fundamental theory of natural selection which states that additive genetic variance (i.e.

344 narrow sense heritability) for traits closely tied to fitness should be close to zero in natural

345 populations at equilibrium (Fisher, 1930; Falconer, 1981). Empirical data from many animal

346 populations also supports this conclusion (Gustafsson, 1986). The observation that this

347 relationship is negative in many decades, however, indicates that there may be a quantity-quality

348 tradeoff for parents. Consistent with this interpretation, each successive child that a parent

349 produced, both shortened the lifespan and lowered the reproduction of all other offspring (Lynch,

350 2016). Furthermore, an individual's reproduction is not expected to be either negatively or

351 strongly positively affected by the LRS of their full aunts and uncles. This is because aunts and

352 uncles are not expected to invest as heavily in their nieces and nephews as they would their own

353 children. In $18^{\text {th }}$ and $19^{\text {th }}$ century Finland, for example, the presence of non-reproductive aunts

354 and uncles was weakly or negatively correlated with the survival of their nieces and nephews

355 (Nitsch et. al. 2014). Therefore, unlike the parent-offspring relationship, niece and nephews are

356 less likely to be negatively impacted by the dilution of investment (e.g. a negative correlation in

357 LRS is evidence of a quantity-quality tradeoff between offspring number and offspring fitness).

358 Therefore, these within family patterns are all broadly consistent with the interpretation that

359 parental investment has had an important impact on fitness in Iceland across the $18^{\text {th }}$ and $19^{\text {th }}$

360 centuries.

361 The observation that the heritability estimates from the correlations between parents and

362 offspring and those among full siblings are positively correlated across time suggests that these

363 two estimates may depend on similar factors. For parents, the amount of investment available

364 per child is diluted when additional offspring are produced. This can generate a negative

365 relationship between parent and offspring reproduction. In contrast, investment is often shared 
366

367

368

369

370

371

372

373

374

375

376

377

378

379

380

381

382

383

384

385

386

387

388

among full siblings which can generate a positive association among siblings. The strong correlation between these two estimates, however, indicates that when PI increases, the quantityquality tradeoff decreases. If parents increase overall investment in offspring, it makes sense that both correlations should increase. Siblings will share a higher level of investment and will therefore reproduce even more similarly, while the quantity-quality tradeoff will also be reduced because overall investment is higher and additional siblings will cost less. The significant longitudinal relationships between the LRS of other relatives (full siblings with half siblings (Figure 2) and full siblings with aunt and uncles (Figure 3) also supports this interpretation. These relationships also appear to respond to mortality shocks. Two peaks of the parentoffspring curve coincide with the two most significant population declines in Iceland between 1700 and 1919: the smallpox epidemic of 1707-1709 with an estimated mortality rate of $26 \%$ (measurement based on all births 1707-1709) (Adalsteinsson, 2007) and the Laki volcanic eruption of 1783 during which approximately $1 / 4$ of the population and $1 / 2$ of the livestock died (Jackson, 1982; Thoranissin, 1961). Survivors of these events may have had more opportunities to acquire resources as the population declined and farmland became available. In Iceland marriage [and hence reproduction] was often tied to owning a farm. (Karlsson, 2000). Therefore, as population density declined new opportunities may have been created which allowed the birth cohort in the following years to be more successful. In addition, parental investment may be less important when population, and therefore competition, is lower. The negative relationships between population wide reproductive rates and both heritability estimates derived from first degree relatives (i.e. parents to offspring and full siblings) provides support for this view. There is also a positive, albeit non-significant, relationship between the population of Iceland and the parent-offspring regression. In other words, when the population increases, the quantity-quality 
389 tradeoff declines (i.e. siblings are less costly to one's fitness). These results are consistent with a 390 study of a lizard population which revealed a cyclical relationship between population density,

391 reproductive effort and investment such that morphs producing few, larger eggs (K selection) are

392 favored at high population densities while those that produce more, but smaller eggs ( $\mathrm{R}$

393 selection) are favored at low densities (Sinervo et al., 2000).

394 There are reasons to be careful when attempting to interpret demographic changes across 395 multiple generations, however. These fluctuations are a complex and dynamic interaction of many factors. For instance, the assumption that wealthier parents should achieve higher LRS (a central tenant of sociobiology) (Nettle and Pollet, 2008), is often violated in contemporary societies where an inverse relationship is now usually seen between family size and wealth (see Vining, 1986). Unfortunately, there were no direct measures on income or material resources for any individuals in the genealogy. Prior to the demographic transition, however, wealthier families probably had more children (Kirk, 1996). If true, this would only serve to reduce the 402 effects observed here because the dilution of resources is reduced when wealthy families have more children. Therefore, these results are likely to be conservative. This may also be one reason why the genealogy often resembles the 'genes and resources' model more than the 'resources only' model. Another reason may be that as Iceland rises above a subsistence level economy in the late $19^{\text {th }}$ and early $20^{\text {th }}$ centuries and resources become more plentiful, the variance of environmental factors which contribute to the denominator in $\mathrm{h}^{2}$ decreases. This would also help to explain previous research revealing higher correlations between the LRS of parents and their offspring in resource rich environments (Tuvblad et. al., 2006; Garcia de Leaniz \& Consuegra, 2006; Charmantier and Garant, 2005; Sgro and Hoffman, 2004; Silventoinen, 411 2003; Merila, 1997). 
412 This study demonstrates that an individual's LRS is best predicted by the reproduction of their

413 full and half siblings. These correlations fluctuate over time which suggests that fertility rates

414 and PI are sensitive to changes in the environment. Future studies can build on these methods

415 and results, expanding both our understanding of the heritability of fitness and the impact of

416 parents. For example, carefully examining the different environmental influences on LRS may

417 help to distinguish between the effects of different types of relatives and common households

418 from those of peer groups. In addition, expanding this analysis to other populations may

419 enhance our understanding of the importance of sibling bonds, while also further teasing apart

420 the root causes of sibling influence on fitness components. Overall, however, these results

421 indicate that parental investment and or resources have had an important impact on the

422 reproduction of offspring in Iceland.

423 Acknowledgments: We are grateful to Kári Stefánsson for access to the database and we

424 thank Agnar Helgason for his assistance with the data analysis.

\section{References}

426

427

428

429

430

431

432 433
Adalsteinsson, S. 2007. Possible changes in the frequency of the human ABO blood groups in Iceland due to smallpox epidemics selection. Annals of human genetics 49 (4): $275-281$.

Åkesson, M., Bensch, S., Hasselquist, D., Tarka, M., \& Hansson, B. 2008. Estimating heritabilities and genetic correlations: comparing the 'animal model' with parentoffspring regression using data from a natural population. PLoS One 3(3): 1739. 
434 Barthold, J. A., Myrskylä, M. and Jones, O. R. 2012. Childlessness drives the sex difference in 435 the association between income and reproductive success of modern Europeans. Evolution and 436 Human Behavior 33(6): 628-638.

437

438

Bolund, E., Bouwhuis, S., Pettay, J. E., and Lummaa, V. 2013. Divergent selection on, but no 439 genetic conflict over, female and male timing and rate of reproduction in a human 440 population. Proceedings of the Royal Society of London B: Biological Sciences, 280 (1772), 44120132002.

442

Bolund, E., Hayward, A., Pettay, J. E., and Lummaa, V. 2015. Effects of the demographic transition on the genetic variances and covariances of human life-history traits. Evolution, 69(3), $445 \quad 747-755$.

446

447 Chapais, B. 2001. The deep social structure of humankind. Science 331(6022): 1276-1277.

449 Charmantier, A. and Garant, D. 2005. Environmental quality and evolutionary potential: lessons 450 from wild populations. Proceedings of the Royal Society of London B: Biological Sciences 451 272(1571): 1415-1425.

452

453

Davis, G. P. 1993. Genetic parameters for tropical beef-cattle in northern Australia — a

454 Review. Australian Journal of Agricultural Research 44: 179-198.

455 
456 Falconer, D. S. 1981. Introduction to quantitative genetics. Longman, LondonFisher, R. A. 1930.

457 A genetical theory of natural selection. Oxford: Oxford University Press.

458 Garcia de Leaniz, C. and Consuegra, S. 2006. Phenotypic variation and population structuring in

459 Atlantic salmon in fluctuating environments. Journal of Fish Biology 69:232-232.

460 Gillespie, D. O., Russell, A. F. and Lummaa, V. 2008. When fecundity does not equal fitness:

461 evidence of an offspring quantity versus quality trade-off in pre-industrial humans. Proceedings

462 of the Royal Society B: Biological Sciences 275 (1635): 713-722.

463

464 Glazier, D. S. 2002. Resource-allocation rules and the heritability of traits. Evolution 56(8):

$465 \quad 1696-1700$.

466

467 Gögele, M., Pattaro, C., Fuchsberger, C., Minelli, C., Pramstaller, P. P., \& Wjst, M. 2011.

468 Heritability analysis of life span in a semi-isolated population followed across four centuries

469 reveals the presence of pleiotropy between life span and reproduction. The Journals of

470 Gerontology Series A: Biological Sciences and Medical Sciences, 66(1), 26-37.

471

472 Guðmundsson, H., Guðbjartsson, D.F., Kong A., Gudbjartsson, H., Frigge, M., Gulcher, J. and

473 Stefansson, K. 2000. Inheritance of human longevity in Iceland. European Journal of Human

474 Genetics 8:743-749.

475

476 Gustafsson, L. 1986. Lifetime Reproductive Success and Heritability: Empirical Support for

477 Fisher's Fundamental Theorem. The American Naturalist 128 (5): 761-767. 
479 Harris, J. R. 1995. Where is the child's environment? A group socialization theory of 480 development. Psychological Review 102(3): 458.

481

482

Helgason, A., Pálsson, S., Guðbjartsson, D. F., \& Stefánsson, K. 2008. An association between 483 the kinship and fertility of human couples. Science, 319(5864), 813-816.

484

485

Henderson, C. R. 1975. Best linear unbiased estimation and prediction under a selection

486 model. Biometrics 423-447.

487

488

Hill, K. R., Walker, R. S., Božičević, M., Eder, J., Headland, T., Hewlett, B. and Wood, B. 2011.

489

Co-residence patterns in hunter-gatherer societies show unique human social structure. Science

490

331(6022): 1286-1289.

491

492

Hill, W. G., Goddard, M. E. and Visscher, P. M. 2008. Data and theory point to mainly additive 493 genetic variance for complex traits. PLoS Genetics 4(2): e1000008.

494

495

Jackson, E. L. 1982. The Laki Eruption of 1783: impacts on population and settlement in 496 Iceland. Geography 67(294): 42-50.

497

498

Karlsson, G. 2000. Iceland's 1100 years: the history of a marginal society. London: Hurst and 499 Company.

500 
501 Kirk, D. 1996. Demographic Transition Theory. Population Studies 50 (3):361-387.

502

503 Kosova, G., Abney, M., and Ober, C. 2010. Heritability of reproductive fitness traits in a human 504 population. Proceedings of the National Academy of Sciences 107(suppl 1): 1772-1778.

505

506

Lai, C. 2011. How much of human height is genetic and how much is due to nutrition? Scientific 507 American, December.

508

509

Lee, R. 2003. The demographic transition: three centuries of fundamental change. The

Journal of Economic Perspectives 17(4): 167-190.

511

512 Lynch, R. F. 2016. Parents face quantity-quality trade-offs between reproduction and investment 513 in offspring in Iceland. Royal Society Open Science, 3(5): 160087.

514

515 Lynch, M. and Walsh, B. 1998. Genetics and analysis of quantitative traits (Vol. 1). Sunderland, 516 MA: Sinauer.

517

518 Merila, J. 1997. Expression of genetic variation in body size of the collared flycatcher under 519 different environmental conditions. Evolution 51: 526-536.

520

521 McNicoll, G. 1992. Changing fertility patterns and policies in the third world. Annual Review of 522 Sociology 85-108. 
524 Milot, E., Mayer, F. M., Nussey, D. H., Boisvert, M., Pelletier, F., \& Réale, D. 2011. Evidence

525 for evolution in response to natural selection in a contemporary human population. Proceedings

526 of the National Academy of Sciences, 108(41), 17040-17045.

527

528 Moorad, J. A., Promislow, D. E., Smith, K. R., \& Wade, M. J. 2011. Mating system change

529 reduces the strength of sexual selection in an American frontier population of the 19th

530 century. Evolution and Human Behavior 32(2): 147-155.

531

532 Moring, B. 2003. Nordic family patterns and the north-west European household

533 system. Continuity and Change 18(01):77-109.

534

535 Mousseau, T. and Roff, D. 1987. Natural selection and the heritability of fitness components.

536 Heredity 59:181-197.

537

538 Nettle, D. and Pollet, T. V. 2008. Natural selection on male wealth in humans. The American

539 Naturalist 172(5): 658-666.

540

541 Nitsch, A., Faurie, C., \& Lummaa, V. 2014. Alloparenting in humans: fitness consequences of 542 aunts and uncles on survival in historical Finland. Behavioral Ecology, art126.

543 Penn, D. J., \& Smith, K. R. 2007. Differential fitness costs of reproduction between the

544 sexes. Proceedings of the National Academy of Sciences, 104(2), 553-558.

545 
546 Price, T. and Schluter, D. 1991. On the low heritability of life-history traits. Evolution 45(4):

$547 \quad 853-861$.

548

549 Raj, A. and Van Oudenaarden, A. 2008. Nature, Nurture, or Chance: Stochastic Gene Expression 550 and Its Consequences. Cell 135 (2): 216-226.

551

552 Rodseth, L., Wrangham, R. W., Harrigan, A. M., Smuts, B. B., Dare, R., Fox, R., and Wolpoff, 553 M. H. 1991. The human community as a primate society [and comments]. Current Anthropology $554 \quad 32(3): 221-254$.

555

556 Roff, D., and Mousseau, T. 1987. Quantitative genetics and fitness: lessons from Drosophila. 557 Heredity 58: 103-118.

558

559 Royle, N.J., Smiseth, P.T. and Kölliker, M. 2012. The Evolution of Parental Care. Oxford: 560 Oxford University Press.

561

562 Salmon, C. A. and Daly, M. 1998. Birth order and familial sentiment: Middleborns are 563 different. Evolution and Human Behavior 19(5): 299-312. 564

565 Sgro, C. and Hoffmann, A. 2004. Genetic correlations, tradeoffs and environmental 566 variation. Heredity 93(3): 241-248. 
568 Sheldon, B. C. 1994. Male phenotype, fertility, and the pursuit of extra-pair copulations by

569 female birds. Proceedings of the Royal Society of London. Series B: Biological Sciences

$570 \quad 257(1348): 25-30$.

571

572 Siguradottir, S., Helgason, A., Gulcher, J.R., Stefansson, K and Donnely, P. 2000. The mutation 573 rate in the human MtDNA control region. American Journal of Human Genetics 66: 1599-1609.

574

575 Silventoinen, K. 2003. Determinants of variation in adult body height. Journal of Biosocial

576 Science 35(02): 263-285.

577

578 Sinervo, B., Svensson, E., and Comendant, T. 2000. Density cycles and an offspring quantity and 579 quality game driven by natural selection. Nature 406(6799): 985-988.

580

581 Smith, J. M. and Price, G. R. 1973. The Logic of Animal Conflict. Nature 246: 15.

582

583 Spitze, K. 1995. Quantitative genetics of zooplankton life histories. Experientia 51:454-464.

584

585

586 Thomas, S. C., Pemberton, J. M., \& Hill, W. G. 2000. Estimating variance components in natural 587 populations using inferred relationships. Heredity, 84(4), 427-436.

589 Thorarinsson, S., 1961. Population changes in Iceland. Geographical Review 51(4): 519-533. 
590 Trivers, R.L. Parental investment and Sexual selection. In B. Campbell (Ed.), Sexual

591 selection and the descent of man, 1871-1971, 1972; (pp. 136-179). Chicago, IL:

592 Aldine.

593

594 Tuvblad, C., Grann, M., and Lichtenstein, P. 2006. Heritability for adolescent antisocial behavior

595 differs with socioeconomic status: gene-environment interaction. Journal of Child Psychology 596 and Psychiatry 47(7): 734-743.

597 Vining, D. R. 1986. Social versus reproductive success: The central theoretical problem of 598 human sociobiology. Behavioral and Brain Sciences 9(01): 167-187.

599

600 Visscher, P. M., Medland, S. E., Ferreira, M. A., Morley, K. I., Zhu, G., Cornes, B. K., and 601 Martin, N. G. 2006. Assumption-free estimation of heritability from genome-wide identity-by602 descent sharing between full siblings. PLoS Genetics 2(3): e41.

603

604 Visscher, P. M., Hill, W. G., and Wray, N. R. 2008. Heritability in the genomics era-concepts 605 and misconceptions. Nature Reviews Genetics 9(4): 255-266.

606

607 Wall, R., Robin, J., and Laslett, P. 1983. Family Forms in Historic Europe. Cambridge 608 University Press.

609

610 Wilson, A. J., Reale, D., Clements, M. N., Morrissey, M. M., Postma, E., Walling, C. A., and

611 Nussey, D. H. 2010. An ecologist's guide to the animal model. Journal of Animal Ecology 79(1): $612 \quad 13-26$. 
613

614 Wray, N. and Visscher, P. 2008. Estimating trait heritability. Nature Education 1(1): 29

615

616 Zaitlen, N., Kraft, P., Patterson, N., Pasaniuc, B., Bhatia, G., Pollack, S., and Price, A. L. 2013.

617 Using extended genealogy to estimate components of heritability for 23 quantitative and

618 dichotomous traits. PLOS Genetics 9(5): e1003520.

619 
Figure 1

Lifetime reproductive success among first degree relatives

The heritability estimates for LRS for first degree relatives $(r=1 / 2)$; (among full siblings and between parents and offspring) were positively correlated across decades.

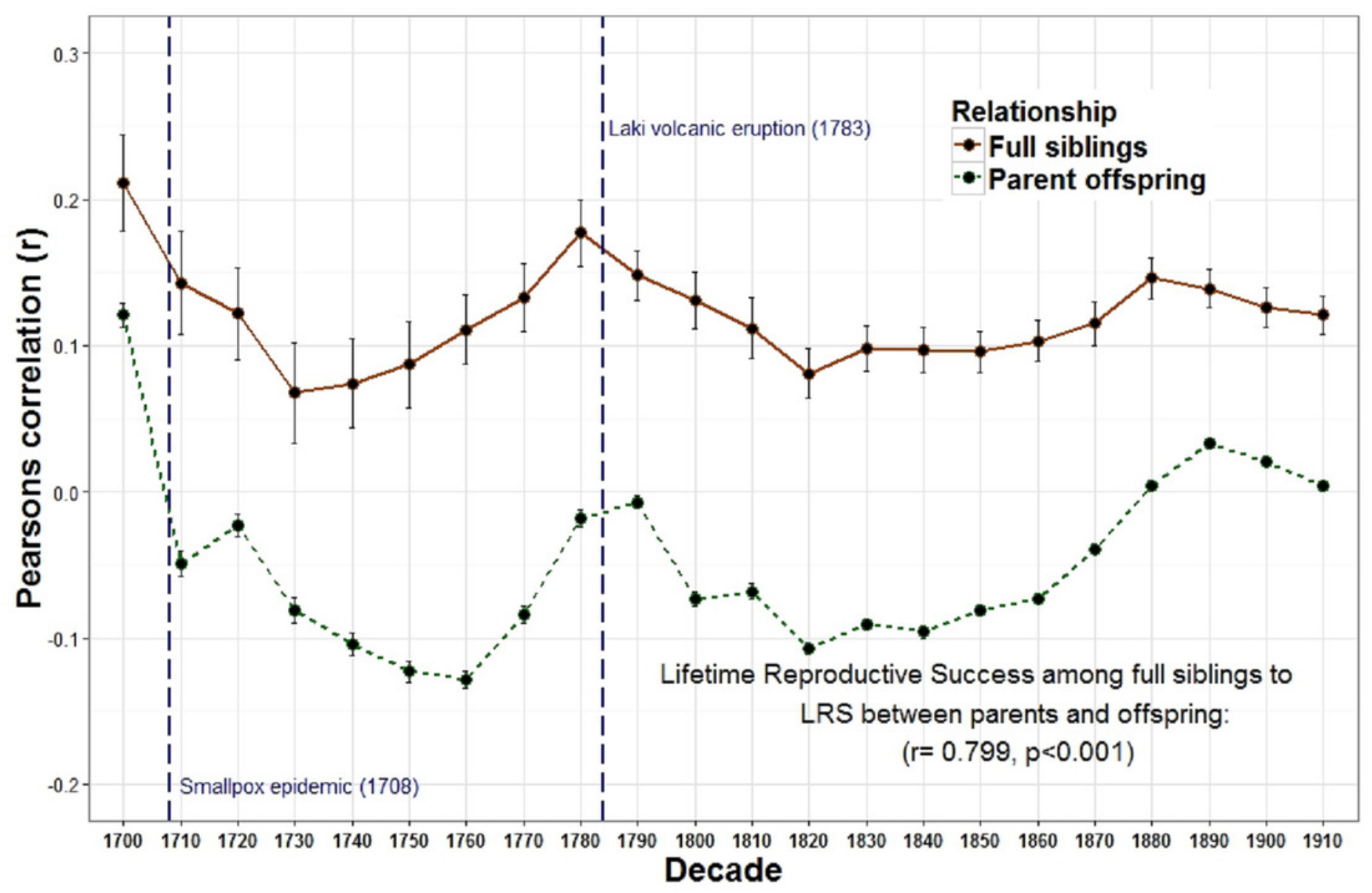


Figure 2

Lifetime reproductive success among full siblings and half siblings

The correlations of LRS among full siblings $(r=1 / 2)$ and those among half siblings $(r=1 / 4)$ were positively correlated across decades.

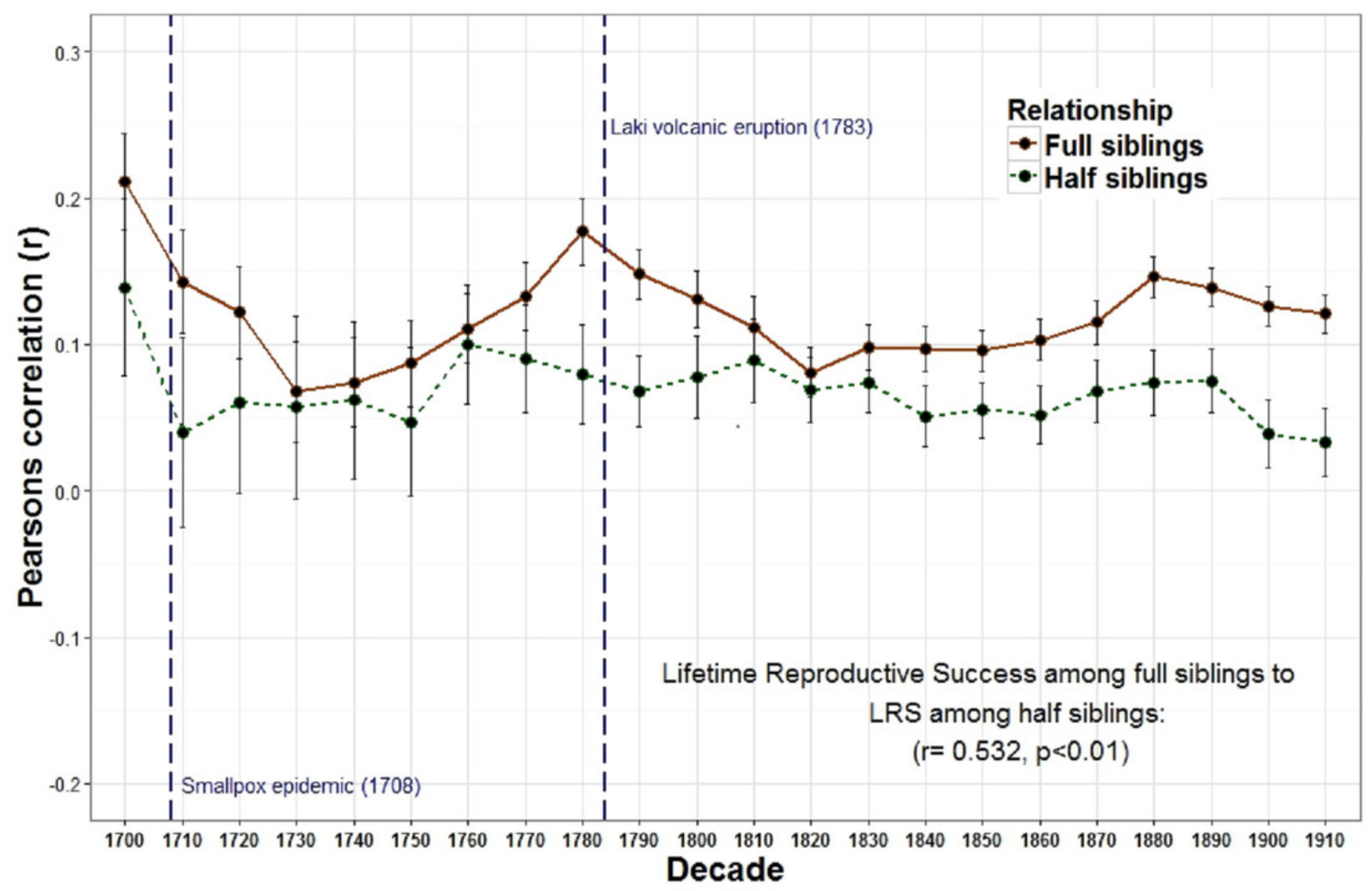


Figure 3

Lifetime reproductive success among full siblings and between aunts, uncles, nieces, and nephews.

The correlations of LRS among full siblings $(r=1 / 2)$ and between aunts and uncles and their nieces and nephews $(r=1 / 4)$ were positively correlated across decades.

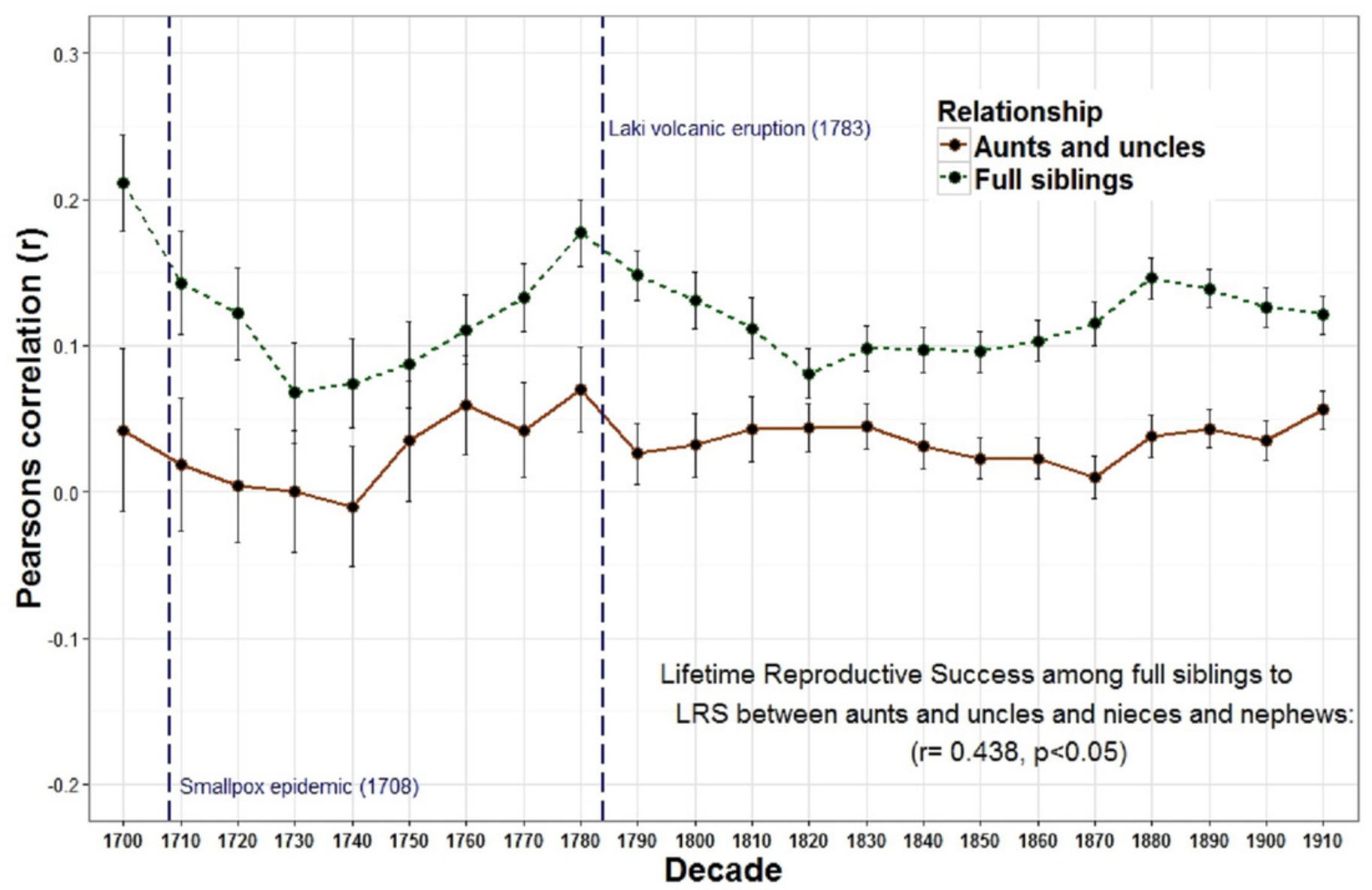




\section{Table $\mathbf{1}$ (on next page)}

Correlation results for lifetime reproductive success across kin types

Relationship between lifetime reproductive success of different categories of first and second degree relatives for all individuals 


\begin{tabular}{|c|c|c|c|c|c|c|}
\hline & $\begin{array}{l}\text { Full } \\
\text { siblings } \\
\text { (all) }\end{array}$ & $\begin{array}{l}\text { Full } \\
\text { siblings } \\
\text { partial } \\
\text { (controlling } \\
\text { for birth } \\
\text { interval) }\end{array}$ & $\begin{array}{l}\text { Parents } \\
\text { (all) }\end{array}$ & $\begin{array}{l}\text { Half } \\
\text { siblings }\end{array}$ & $\begin{array}{l}\text { Aunts and } \\
\text { uncles }\end{array}$ & Grandparents \\
\hline $\begin{array}{l}\text { Lifetime } \\
\text { reproductive } \\
\text { success }\end{array}$ & $\begin{array}{l}0.191 \\
(\mathrm{p}<0.001)^{* *} \\
\mathrm{~N}=153,084\end{array}$ & $\begin{array}{l}0.21 \\
(p<0.001)^{* *} \\
N=153,084\end{array}$ & $\begin{array}{l}0.00 \\
(p=0.08) \\
N=163,081\end{array}$ & $\begin{array}{l}0.07 \\
(\mathrm{p}<0.001)^{* *}\end{array}$ & $\begin{array}{l}0.03 \\
(\mathrm{p}<0.001)^{* *}\end{array}$ & $\begin{array}{l}0.01 \\
(p<0.01)^{*} \\
N=158,571\end{array}$ \\
\hline
\end{tabular}

1 


\section{Table 2 (on next page)}

The relationship between birth interval on the reproduction of full siblings 


\begin{tabular}{|l|l|l|l|}
\hline & Resources(s.e) & Genes(s.e) & Genes and resources (s.e) \\
\hline Parent-offspring & $\mathrm{r}=-0.35(0.02)$ & $\mathrm{r}=0.185(0.03)$ & $\mathrm{r}=0.06(0.03)$ \\
\hline Full siblings & $\mathrm{r}=0.28(0.03)$ & $\mathrm{r}=0.20(0.03)$ & $\mathrm{r}=0.21(0.02)$ \\
& & & \\
\hline
\end{tabular}

